\title{
Digitalizando los datos en la gestión de donantes de sangre: ¿Lujo o necesidad?
}

\author{
Digitizing the data in the management of blood donor: Luxury or necessity?
}

\section{Sr. Editor:}

La donación de sangre es un acto altruista, voluntario y libre de reembolso, lo cual implica con un mayor grado de probabilidad, la obtención de sangre segura $(1,2)$. No obstante, muchos países en desarrollo, como el Perú, todavía dependen de donaciones relativamente poco seguras (3). Durante el año 2004 en el Perú solo el 3,9\% de sangre provino de donaciones voluntarias, lo cual implica un alto porcentaje de donaciones por reposición (4).

Se pueden caracterizar 2 tipos de donantes de acuerdo a su intención: voluntario y de reposición. El voluntario, es principalmente captado y fidelizado en campañas de donación de sangre, mientras que, el donante de reposición puede ser un familiar, amigo o tercero, que obligado, coaccionado o remunerado, acude a un banco de sangre para reponer la sangre utilizada (5).

Debido a la exigencia institucional y al número insuficiente de familiares-donantes para cumplir con la cantidad de sangre solicitada, es de suponer que los familiares de los pacientes pueden buscar a terceras personas para que asistan a "donar", con una retribución económica. Este hecho, pagar por "donar", puede interesar a personas que motivadas por el lucro acudan a vender su sangre.

También, es de suponer que los "donantes" remunerados consuetudinarios pueden conocer el proceso de selección, por lo que podrían dar información falsa con el fin de ocultar su identidad o conductas de riesgo. Sin duda alguna, esto representa un grave riesgo para la salud pública y medicina transfusional. En tal sentido, consideramos que optimizando la perspicacia del entrevistador y adaptando un sistema informático para la gestión de datos, el riesgo de la donación remunerada puede ser reducido a su mínima expresión.

El rol del entrevistador, entre otros, es detectar conductas o signos que hagan suponer de falsos datos reportados. Aun así, es probable la existencia de "donantes" remunerados que hayan aprendido a superar este primer filtro.

La implementación de un sistema informático puede ayudar a mejorar los procesos, el flujo de trabajo en la disposición de hemoderivados y es fácilmente adaptable a las necesidades particulares de cada banco de sangre $(6,7)$, del mismo modo, podría mejorar la gestión de datos del donante en la admisión; recuperando información sobre elegibilidad, motivos de rechazo reciente, tiempo por el cual fue diferido, historial de donaciones correlacionada con los diversos receptores para los cuales donó, y otros datos relevantes para su aceptación como donante. $\mathrm{Su}$ aplicación podría permitir la gestión de manera descentralizada, integral y en tiempo real de los datos de todo potencial donante con una base nacional de identidades. Sin duda, esta herramienta permitiría optimizar el primer filtro con el fin de asegurar donaciones seguras a través de la disminución de "donantes" remunerados consuetudinarios. Sin embargo, se requieren de estudios que evalúen el costo-beneficio de la implementación informática de manera local, regional y nacional.

Finalmente, con el fin de obtener con mayor probabilidad un alto número de donaciones seguras, consideramos que la investigación e inversión enfocada a plantear mejoras en los procesos de selección e identificación del potencial donante de sangre debe ser continua, y sustentado en los actuales lineamientos del Programa Nacional de Hemoterapia y Bancos de Sangre. No obstante, sugerimos la constante implementación de medidas en los programas actuales que permitan la educación de la población con respecto a la importancia de la donación voluntaria de sangre y la no remuneración con tal fin.

Steev O. Loyola-Sosa

Licenciado Tecnólogo Médico. Egresado de la Escuela de Tecnología Médica. Facultad de Medicina. Universidad Peruana Cayetano Heredia. Lima, Perú. 
Jose A. Paredes Arrascue

Licenciado Tecnólogo Médico. Hospital Nacional

Edgardo Rebagliati Martins. Servicio de Medicina

Transfusional. Profesor Asociado, Facultad de

Medicina. Cátedra de Inmunohematología.

Universidad Nacional Mayor de San Marcos. Lima,

Perú.

\section{Correspondencia:}

José Antonio Paredes Arrascue

Jr. José M. Quiroga N. 227. Lima 01

jparadesa@unmsm.edu.pe

\section{REFERENCIAS BIBLIOGRÁFICAS}

1. Congreso de la República del Perú. Ley de Fomento de la Donación de Órganos y Tejidos Humanos. Ley No 27282. Lima: Congreso de la República (Internet). (Citado el 05 de enero de 2014); Disponible en: http:// www.minsa.gob.pe/portada/Especiales/2010/ donacion/DocInteres/LeyFomentoDonOrganos.pdf

2. Ribera J, Roca O. La experiencia del Perú con un programa nacional de bancos de sangre. Rev Panam Salud Pública. 2003; 13 (2-3):165-71.
3. Organización Mundial de la Salud. Disponibilidad y seguridad de la sangre a nivel mundial. Ginebra: Organización Mundial de la Salud; Noviembre 2009 (Citado el 28 de diciembre de 2013); Disponible en: http://www.who.int/mediacentre/factsheets/fs279/es/

4. Ministerio de Salud. Dirección General de Salud de las Personas. Dirección de Servicios de Salud. Lineamientos Políticos del PRONAHEBAS. Lima: Ministerio de Salud; 2007 (Internet). (Citado el 28 de diciembre de 2013); Disponible en: http://bvs.minsa. gob.pe/local/MINSA/1087_DGSP264.pdf

5. García M, Sáenz de Tejada E, Ramiro J. Estudio de factores socioculturales relacionados con la donación voluntaria de sangre en las Américas. Rev Panam Salud Publica. 2003, 13(2-3):85-90.

6. Li BN, Chao S, Chui Dong M. SIBAS: a blood bank information system and its 5-year implementation at Macau. Comput Biol Med. 2007; 37 (5):588-97.

7. Clark IR, Parekh J, Peters M, Frew I, Ibbotson RN. Hospital blood bank laboratory data processing system. J Clin Pathol. 198; 37 (10):1157-66. 